\title{
The Effectiveness Companion of Cognitive Behavioral Interventions and the Sensory Processing Styles Training on Behavioral Problems in Children Aged 7-12 Years
}

\author{
Nasrin Eghbali Ghazijahani, Ramazan Hassanzadeh*, Yarali Doosti \\ Department of Psychology, Sari Branch, Islamic Azad University, Sari, Iran
}

\begin{abstract}
Background: Children's health is very important in societies. Children's behavioral problems result in efficiency rate reducing in educational performance. Therefore, solving these problems is necessary. This study aimed to compare the effectiveness of cognitive-behavioral interventions and sensory processing styles training on children's behavioral problems (7-12 aged).

Methods: The current study was quasi-experimental with the pretest-posttest design. The statistical population of this research included all elementary students of sari city in 2017-2018. Among them, 90 target students (30 students per intervention) were selected as samples by the clustering sampling method and were randomly assigned to control and experimental groups. Experimental groups received cognitive-behavioral interventions and sensory processing styles training orderly. Control group received no training. A child behavioral questionnaire was used to collect information. After scoring the questionnaire and extracting the data, SPSS-21 software used for statistical analysis of multivariate covariance and independent $t$ test.

Results: The findings showed that cognitive-behavioral interventions and the training of sensory processing styles have a significant effect on behavioral problems in children and have reduced the internalization and extraversion problems in experimental groups and the effectiveness of the cognitive-behavioral intervention in reducing behavioral problems in children is more significant than teaching sensory processing styles.

Conclusion: We suggest that cognitive-behavioral therapy and sensory processing styles training are useful for parents. They help to thought control, ethical behavior and parents, mental health.

Keywords: Cognitive-behavioral interventions; Sensory processing styles; Behavioral problems.
\end{abstract}

*Correspondence to Ramazan Hassanzadeh, Department of Psychology, Sari Branch, Islamic Azad University, Sari, Iran. Tel: 0113303 3729; Email:

rhassanzadehd@yahoo.com

Published online 20 March 2019

Citation: Eghbali Ghazijahani N, Hassanzadeh R, Doosti Y. The effectiveness companion of cognitive behavioral interventions and the sensory processing styles training on behavioral problems in children aged 7-12 years. Int Clin Neurosci J. 2019;6(1):11-16. doi:10.15171/icnj.2019.03

\section{Introduction}

Children health is very important in societies. Because of childhood experience effect on physical and mental health. ${ }^{1}$ Society's problems have resulted in severe problems, especially for children and juveniles. ${ }^{2,3}$ The behavioral problem results in mental and behavioral imbalance and has intensity, repetition, and duration. It results in efficiency rate reducing in educational and behavioral performance, the other persons reject these children directly or indirectly and complain about them in schools. ${ }^{4}$ Behavioral disorders result in individual- social problems. These children make vulnerable their families against mental-social disturbance. ${ }^{5}$ Of course, activebehavioral disorders decrease children's ability social, educational and emotional performance. ${ }^{6}$ Some problems such as attention failure, hyperactivity, conduct disorder, generalized anxiety, depression, fear that may be appeared as beating, screaming, sabotage, threating, school dropout and negativism. These states may be known as behavioral problems if they become spontaneous and constant. ${ }^{7}$ Difference factors explain children's behavioral problems like parenting factor, ${ }^{8}$ maternal anxiety and depression, ${ }^{9}$ teacher's attitude, ${ }^{10}$ family relationships and environment. ${ }^{11}$ In one study in England, $7 \%$ of preschool children showed moderate was $8.6 \% .^{12} 1.4 \%$ of Iranian children show behavioral disorders. The disorders rate is equal among boys and girls and has been greater in cities children than rural children. Also, the disorder rate in first grade has been more significant than the other levels. ${ }^{13}$ Today different attitudes like cognitive-behavioral interventions and sensory processing styles training use to confront children behavioral problems. Cognitivebehavioral methods have been successful in behavioral problems therapy, cognitive-behavioral attitude regards to believes, opinions. This hell theorists believe that the interpretation way is essential, communicating with clients and wanting them to state their thoughts feelings and then defining basic believes and their relations with 
current problems and finally removing inefficient believes are very important. ${ }^{14}$ Cerel and colleagues studied in juveniles emotional disorders. ${ }^{14}$ Rossell and colleagues studied in juveniles emotional problems and depression ${ }^{15}$; Franklin and colleagues studied on obsessive children ${ }^{16}$; Qutaiba $^{17}$ on conduct problems reducing, hyperactivity and aggression among juveniles; and Sarihi and colleagues $^{5}$ on preschool children behavioral problems have shown this method effectiveness.

Training of sensory processing styles is the other kind of intervention on children's behavioral problems. This style is one method that the neurological system receives neurological inputs, explains and responses to them. ${ }^{18}$ Sensory processing sensitivity explains an individual's differences in the sensory processing style. This kind of sensitivity is known as the personality mood feature that is defined by sensitivity toward internal and external excitations such as emotional and social stimulants. ${ }^{19}$ Individuals may be active or passive in responding to sensory stimulants. This state results in 4 styles of sensory processing that explain child behavior; these 4 styles are: sensitivity sensitive low threshold, and active strategy, sensory checker (high threshold and active strategy) and low recording (high threshold and passive strategy). ${ }^{20}$ Therefore, sensory processing is important in human behavior. ${ }^{21}$

Furthermore, the behavioral-emotional problem emerges through sensory and motor processing problems. ${ }^{22}$ Sensory problems may result in using self-stimulation and avoidance. ${ }^{23}$ Liss and colleagues ${ }^{24}$ showed that sensory processing sensitivity might result in being vulnerable to environment stimulants and finally become excited rapidly. Pluess and Boniwell found that sensory processing sensitivity is an important predictor for responding to therapeutic interventions. Also, the individual's personality features are important for successful sensory processing. ${ }^{25}$ Dehghan and colleagues found that there is significant difference between normal children scores average and autistic children in sensory item, excitation, low muscular tolerance, oral sense sensitivity, distraction, sensory register weakness and subtle movements and sensory- acceptance and excitation factors have the most relations with autistic children behavioral problems. ${ }^{26}$ Molagholamreza Tabasi and colleagues showed that deficiency in sensory processing might result in ADHD children behavioral symptoms. ${ }^{27}$ With regard to contradictory results and little research in this field, it is necessary to compare these two methods. Therefore this study aimed to compare the effectiveness of cognitive- behavioral interventions and the training of sensory processing styles on children's aged 7-12 years of behavioral problems.

\section{Methods}

The current study was quasi-experimental with the pretest-posttest design. The statistical population of this research includes all elementary students of Sari city. Among them, 90 target students with behavioral problems (30 students per intervention) were select by cluster sampling method and were randomly assigned to control and experimental groups. Entrance criteria to research are: identification of behavioral problems, 7-11 ages and exclusion criteria from research: disorder or illness that may result in creating problems on research, being absent more than 2 sessions, after executing pretest, mothers with children with behavioral problems, 10 cognitivebehavioral interventions session during 2 months (each week, one session 2 hours). The second experimental group received. Eight sessions from sensory processing styles training, while the control group received no intervention. After completing sessions, the posttest executed upon three groups. Data analysis completed by multivariate covariance test and independent $\mathrm{t}$-test with SPSS-21.

The content of cognitive-behavior sessions has been shown in Table $1 .{ }^{28}$ Also, the content of sensory processing styles training sessions has shown in Table 2.

\section{Child Behavior Checklist}

The used instrument in this research was the Child Behavior Checklist (CBCL). CBCL has been designed to define child adjustment way with the environment. ${ }^{29}$ This questionnaire does not classify children with one particular syndrome. It classifies a set of child behaviors.

Table 1. Sessions of Cognitive-Behavioral Interventions

\begin{tabular}{ll}
\hline Session & Session Subject \\
\hline Session 1 & Introducing children to each other, executing children's suggestive plays to create a close relationship and security feeling. \\
Session 2 & Using toys logos to create group cooperation feeling in children and removing aloofness behaviors \\
Session 3 & $\begin{array}{l}\text { Children were encouraged to make their interesting shapes by play dough and then explained about their make shapes and admired by } \\
\text { the other children }\end{array}$ \\
Session 4, 5 & $\begin{array}{l}\text { Musical play executed upon participants (rotating music sound around the chair and sit down chair with finishing music sound, finding } \\
\text { hidden thing by the child with changing music sound }\end{array}$ \\
Session 6 & $\begin{array}{l}\text { There were executed some matches among them by manual work (colored paper scissor, cardboard, and glue). Children selected the } \\
\text { best manual work, and finally, all manual works were encouraged. }\end{array}$ \\
Session 7, 8 & $\begin{array}{l}\text { They have trained the best social behaviors of children by pups dolls. } \\
\text { Session 9, 10 }\end{array}$ \\
\hline
\end{tabular}


Table 2. Sensory Processing Styles Training

\begin{tabular}{|c|c|}
\hline Session & Session Subject \\
\hline Session 1 & $\begin{array}{l}\text { Program's total goals/following self-closing play imitation/playing with others/stimulating vestibular system/coordination eye and } \\
\text { hand, concentration, move mental planning, spatial consciousness and stimulating vestibular/purposive activity with others, balances, } \\
\text { powerness, sense input, consciousness from cause and effect/reinforcing linguistic skills/tolerating unexpected experiences }\end{array}$ \\
\hline Session 2 & $\begin{array}{l}\text { Understanding beginning and finishing, individual body adjustment to create some spaces with different values/standing experience } \\
\text { in one line beside the others, increasing deep sense input trust to the other, helping to other to have happy experiences, expecting for } \\
\text { time/concentration, obtaining to goals, coordination eye and hand, giving time/coordination eye and foot, identification colors, giving } \\
\text { time, spatial consciousness more mental adjustment to jump to longer distance }\end{array}$ \\
\hline Session 3 & $\begin{array}{l}\text { Stimulation touch, reducing touch defense, body sensuousness, organizing mind and body, relaxation/more mental planning, } \\
\text { flexibility, balance, concentration, discriminating situations/following instructions/predicting goal, more mental planning/deep sense } \\
\text { feedback, experiencing new things/imitation to listen to audial signs }\end{array}$ \\
\hline Session 4 & $\begin{array}{l}\text { Deep sense touch, body consciousness, paying attention self-closing play/coordination eye and hand, playing with partner, } \\
\text { deep sense visual stimulating, shaping to goal, identification shapes, consciousness increasing toward environment, working by } \\
\text { coordination eye and hand, consciousness from cause and effect, coordination eye and hand, visual discrimination/move mental } \\
\text { control, listening to instructions, imitation from other, audial, visual movement/improving muscle control-obtaining goal }\end{array}$ \\
\hline Session 5 & $\begin{array}{l}\text { Predicting results, understanding concepts inside, outside and beside, tolerating failure/predicting action, coordination eye and hand, } \\
\text { concentration/move mental control, discriminating among rapid, slow and stopping movements, listening to verbal signs-imitation } \\
\text { from body movements, using energy/understanding rapid concept, understanding physical sense from stopping/identifying self in } \\
\text { mirror, experiencing from self-reaction }\end{array}$ \\
\hline Session 6 & $\begin{array}{l}\text { Learning different names of other persons, improving self-learning sense enjoying from new experiences/conjoint attention, eye } \\
\text { coordination, spatial consciousness/controlling respiration, the group working, understanding actions results/paying attention to items, } \\
\text { visual stimulation, spatial consciousness, increasing subtle move mental control/giving time, sorting }\end{array}$ \\
\hline Session 7 & $\begin{array}{l}\text { Playing, subtle move mental control, identification two- steps process/listening, identification, audial sense stimulating, group match/ } \\
\text { playing with other, touch stimulating, touch sensitivity reducing/visual stimulating, naming things/touch defense reducing, touch } \\
\text { consciousness increasing, subtle movements control. }\end{array}$ \\
\hline Session 8 & $\begin{array}{l}\text { Reinforcing linguistic skills, stimulating, sense and giving time, listening to rhythm, oral control, following instruction, creativity } \\
\text { encouragement. }\end{array}$ \\
\hline
\end{tabular}

The primary respondent is the child's father or mother. $\mathrm{He} / \mathrm{she}$ helps to identify child behavioral. Problem. This instrument consists of 116 items (yes, sometime, no) with 0-2 scores orderly. This questionnaire scores calculated for 2 entire fields including internalization and externalization problem. Coefficient $\alpha$ for all instrument and two fields, internalization \& externalization problems have been reported $0.86,0.85$ and 0.87 orderly. Mothers completed this questionnaire at two stages including preintervention and past-intervention stages. ${ }^{30}$

Table 3. Subjects Frequency Distribution Based On Studied Groups

\begin{tabular}{lcc}
\hline \multirow{2}{*}{ Groups } & \multicolumn{2}{c}{ Age Group } \\
\cline { 2 - 3 } & $\mathbf{7 0 - 1 0}$ & $\mathbf{1 1 - 1 2}$ \\
\hline Cognitive-behavioral therapy & 19 & 11 \\
Sensory processing styles training & 17 & 13 \\
\hline
\end{tabular}

\section{Results}

Table 3 shows subjects age frequency at studied groups (cognitive-behavioral therapies \& sensory processing styles training). As is seen, most subjects were in the age range of 7 to 10 .

Table 4 shows the mean and standard deviation of behavioral problems, externalization \& internalization problems for experimental \& control at pretest and posttest. As it is clear, experimental group scores are greater than control group scores in behavioral problems.

According to Table 5, there is significant difference between experimental and control groups in behavioral problems dimension $(P \leq 0.000 \mathrm{~F}=43.65, \mathrm{df}=1.28)$ and 2 subscales, externalization $(P \leq 0.000, \mathrm{~F}=36.69, \mathrm{df}=1.28)$ and internalization $(P \leq 0.000, \mathrm{~F}=33.88, \mathrm{df}=1.28)$. The effective rate in the behavioral problems dimension is 60 , i.e., $60 \%$ difference between experimental and

Table 4. The Mean and Standard Deviation of Behavioral Problems for Experimental and Control Groups at Pretest and Posttest

\begin{tabular}{|c|c|c|c|c|c|c|c|c|c|}
\hline \multirow{3}{*}{ Research Variables } & & \multicolumn{4}{|c|}{ Experimental Group } & \multicolumn{4}{|c|}{ Control Group } \\
\hline & & \multicolumn{2}{|c|}{ Pre-test } & \multicolumn{2}{|c|}{ Post-test } & \multicolumn{2}{|c|}{ Pre-test } & \multicolumn{2}{|c|}{ Post-test } \\
\hline & & Mean & SD & Mean & SD & Mean & SD & Mean & SD \\
\hline \multirow{3}{*}{$\begin{array}{l}\text { Cognitive-behavioral } \\
\text { therapy }\end{array}$} & Externalization & 53 & 1.24 & 24.06 & 5.58 & 61.20 & 1.20 & 44.73 & 1.15 \\
\hline & Internalization & 70.53 & 1.26 & 31.80 & 1.20 & 70.60 & 1.24 & 55.13 & 1.39 \\
\hline & Behavioral Problems (total) & 5.86 & 1.33 & 1.21 & 2.22 & 11.31 & 2.16 & 9.53 & 2.11 \\
\hline \multirow{3}{*}{$\begin{array}{l}\text { Sensory processing styles } \\
\text { training }\end{array}$} & Externalization & 48.53 & 1.14 & 29.20 & 7.47 & 73 & 1.63 & 68.80 & 2 \\
\hline & Internalization & 84.53 & 2.37 & 63.06 & 1.93 & 87.20 & 2.18 & 87 & 1.89 \\
\hline & Behavioral problem (Total) & 9.26 & 3.07 & 1.33 & 2.43 & 1.60 & 3.65 & 1.55 & 3.55 \\
\hline
\end{tabular}


Table 5. Covariance Analysis Results Between the Experimental Group (CBT) and the Control Group

\begin{tabular}{|c|c|c|c|c|c|c|c|}
\hline & & $d f$ & SS & MS & $\mathbf{F}$ & $P$ Value & Eta \\
\hline \multirow{3}{*}{ Pre-test score } & Externalization & 1 & 504.30 & 504.30 & 3.55 & 0.07 & 0.107 \\
\hline & Internalization & 1 & 0.033 & 0.033 & 0.000 & 0.98 & 0.000 \\
\hline & Behavioral problems (total) & 1 & 740.03 & 740.03 & 1.53 & 0.225 & 0.152 \\
\hline \multirow{2}{*}{$\begin{array}{l}\text { Intervention } \\
\text { score }\end{array}$} & Externalization & 1 & 35500.80 & 35500.80 & 428.85 & 0.000 & 0.939 \\
\hline & Internalization & 1 & 56680.53 & 56680.53 & 331.59 & 0.000 & 0.922 \\
\hline \multirow{4}{*}{ Group } & Behavioral problems (total score) & 1 & 48310.30 & 48310.30 & 1 & 0.000 & 0.953 \\
\hline & Externalization & 1 & 3203.33 & 3203.33 & 38.69 & 0.000 & 0.580 \\
\hline & Internalization & 1 & 4083.33 & 4083.33 & 33.88 & 0.000 & 0.460 \\
\hline & Behavioral problems (total score) & 1 & 13653.33 & 13653.33 & 43.65 & 0.000 & 0.609 \\
\hline \multirow{3}{*}{ Error } & Externalization & 28 & 2317.86 & 82.78 & & & \\
\hline & Internalization & 28 & 4786.13 & 170.93 & & & \\
\hline & Behavioral problems (total score) & 28 & 8757.46 & 312.76 & & & \\
\hline \multirow{3}{*}{ Total } & Externalization & 30 & 41022 & & & & \\
\hline & Internalization & 30 & 65550 & & & & \\
\hline & Behavioral problems (total score) & 30 & 201206 & & & & \\
\hline
\end{tabular}

SS, Sum squares; MS, Mean squares.

control group scores at posttest is related to the cognitivebehavioral intervention effect. The effective rate in externalization subscale is 58 , i.e., a $58 \%$ difference between experimental and control group score at posttest is related to the cognitive-behavioral intervention effect. The effective rate in internalization is 46 , i.e., a $46 \%$ difference between experimental and control group score at posttest is related to the cognitive-behavioral intervention effect. Therefore research hypothesis, i.e., the effectiveness of cognitive-behavioral intervention problem on children's behavioral problem is approved.

Table 6 shows that is significant difference between experimental and control group in behavioral problems dimension $(P \leq 0.000, \mathrm{~F}=32.64, \mathrm{df}=1.28)$ and 2 subtest externalization $(P \leq 0.000, \quad \mathrm{~F}=51.20, \mathrm{df}=1.28) \quad$ and internalization $(P \leq 0.000, \mathrm{~F}=11.70, \mathrm{df}=1.28)$. Results show that the effective rate in behavioral problems dimension is 53 , i.e., $53 \%$ difference between experimental and control group score at posttest is related to the effect of sensory processing styles training. The effective rate in externalization subscale is 64 i.e., $64 \%$ difference between experimental and control groups score at posttest is related to the effect of sensory processing styles training. The effective rate in internalization is 29 , i.e., $29 \%$ difference between experimental and control group scores at posttest is related to the effect of sensory processing styles training. Therefore, the research hypothesis based on the effectiveness of sensory processing styles training upon children's behavioral problems is approved.

It was used the independent $t$ test to define the effectiveness of 2 therapy methods. Levene test results show that it is significant between the effective rate of cognitive-behavioral interventions and sensory processing styles training $(P<0.0001)$. The means show that cognitive-behavioral interventions that sensory processing training upon children's behavioral problem

Table 6. Results of Covariance Analysis Between Experimental Groups

\begin{tabular}{|c|c|c|c|c|c|c|c|}
\hline & & $d f$ & SS & MS & $\mathbf{F}$ & $P$ Value & Eta \\
\hline \multirow{3}{*}{ Pretest score } & Externalization & 1 & 4489.63 & 4489.63 & 22.59 & 0.0001 & 0.447 \\
\hline & Internalization & 1 & 53.33 & 53.33 & 0.102 & 0.751 & 0.004 \\
\hline & Behavioral problems (total score) & 1 & 5776.03 & 5776.03 & 4.88 & 0.035 & 0.149 \\
\hline \multirow{2}{*}{ Intervention score } & Externalization & 1 & 72030 & 72030 & 313.62 & 0.0001 & 0.918 \\
\hline & Internalization & 1 & 169800.03 & 169800.03 & 460.08 & 0.0001 & 0.943 \\
\hline \multirow{4}{*}{ Group } & Behavioral problems (total score) & 1 & 461528.03 & 461528.03 & 497.61 & 0.0001 & 0.947 \\
\hline & Externalization & 1 & 11761.20 & 11761.20 & 51.20 & 0.0001 & 0.647 \\
\hline & Internalization & 1 & 4296.03 & 4296.03 & 11.70 & 0.002 & 0.295 \\
\hline & Behavioral problems (total score) & 1 & 30273.63 & 30273.63 & 32.64 & 0.0001 & 0.538 \\
\hline \multirow{3}{*}{ Error } & Externalization & 28 & 6430.80 & 229.607 & & & \\
\hline & Internalization & 28 & 10278.93 & 367.10 & & & \\
\hline & Behavioral problems (total score) & 28 & 25969.33 & 927.47 & & & \\
\hline \multirow{3}{*}{ Total } & Externalization & 30 & 90222 & & & & \\
\hline & Internalization & 30 & 183475 & & & & \\
\hline & Behavioral problems (total score) & 30 & 517771 & & & & \\
\hline
\end{tabular}

SS, Sum squares; MS, Mean squares. 
Table 7. Comparing Results of 2 Interventions Including Cognitive-Behavioral and Sensory Processing Training

\begin{tabular}{|c|c|c|c|c|c|c|c|c|}
\hline Groups & Number & Mean & Levene & Sig. & $d f$ & $t$ & $P$ Value & Means Difference \\
\hline Cognitive-behavioral & 15 & 52.93 & 5.31 & 0.029 & 28 & 5.78 & 0.0001 & -39.33 \\
\hline Sensory Processing styles training & 15 & 92.36 & & & & & & \\
\hline
\end{tabular}

problems reducing has been more effective (Table 7).

\section{Discussion}

Results showed that hypothesis 1 is approved. Cognitivebehavioral interventions are effective upon children's behavioral interventions. The most effect of cognitivebehavioral therapy shown in behavioral problems, externalization, and internalization with Zareh and Ahmadi research orderly. This finding is consistent. Results based on cognitive-behavioral therapy is effective upon children's behavioral problems. ${ }^{28}$ Also, Cerel et al have confirmed the effect of cognitive-behavioral interventions on depression and emotional problems reducing among juveniles. ${ }^{14}$ Qutaiba stated that cognitivebehavioral interventions effect upon conduct problems, hyperactivity and aggression reducing among juveniles. ${ }^{17}$ Gallagher et al found the cognitive-behavioral therapy is effective on children's social fear reducing. ${ }^{31}$ Spence and colleagues stated that the cognitive-behavioral problem is effective on behavioral problems internalized subscale reducing such as anxiety. ${ }^{32}$ Cognitive-behavioral therapy is very important among psychological therapies. Based on cognitive-behavioral therapy, individuals experiences results in creating some schemes about self and world. These schemas effect on the perceptual organization, control, and behavior appraisal. This therapy removed cognitive from individual and used some behavioral techniques such as deviating attention and solvingproblem, this therapy teaches reviewing and self-regulation to the patient. Hypothesis 2, i.e., sensory processing styles training is effective in children's behavioral problems was approved. The most significant effect of processing styles training has been in behavioral problems, externalization and internalization dimensions, and these results are consistent with Baker and colleagues research about the effect of sensory processing styles for children with internalized behavioral problems (depressed \& anxious). They found that depressed and anxious juveniles show conscious avoidance. ${ }^{22}$ Also, they are consistent with Mahmoodi and colleagues research results ${ }^{33}$ and Liss et $\mathrm{a}^{24}$ study on children with behavioral problems. Children with behavioral disorders confront their families with different problems and make them vulnerable toward mental-social derangements. Training techniques are useful to solve them. According to the results, hypothesis 3 approved, i.e., there is a significant difference between the effective rate of cognitive-behavioral interventions and sensory processing styles training. Cognitivebehavioral interventions then sensory processing styles training has been more active on children's behavioral problems reducing. This finding is consistent with Rathod et $a l^{34}$ research about the comparison of sensory integration interventions with cognitive-behavioral therapy among individuals with ADHD that have shown cognitive-behavioral therapy effect more than the sensory integration interventions. ${ }^{34}$ Two of the most critical research limitations are studied case (students) and geographic research region (Sari city) that make difficult results generalization.

\section{Conclusion}

We can state that children's behavioral problems reduced by training equipment's, it is also suggested to teach cognitive-behavioral therapy periods and sensory processing styles training. This training helps to control thoughts and to create a parent's mental health. These effective supports may result in better understanding parent's feelings and performance toward their children and also better adjustment with these children conditions.

\section{Conflict of Interest Disclosures}

The authors declare that they have no conflict of interests.

\section{Ethical Statement}

All ethical principles considered in this article. The participants were informed about the purpose of the research and its implementation stages and signed the informed consent; they also assured about the confidentiality of their information; Moreover, They were allowed to leave the study whenever they wish, and if desired, the results of the research would be available to them.

\section{References}

1. Heydari J, Azimi H, Mahmoudi G, Mohammadpour RA. Prevalence of behavior-emotional disorders and its associated factors among the primary school students of Sari township in 2006. Journal of Mazandaran University of Medical Sciences. 2007;16(56):91-100.

2. Rezaei T, Yazdi-Ravandi S, Ghaleiha A, Seif Rabiei MA. Depression among medical students of Hamadan University of Medical Sciences in 2014: The Role of demographic variables. Pajouhan Scientific Journal. 2015;13(4):1-8.

3. Azami E, Hajsadeghi Z, Yazdi-Ravandi S. The comparative study of effectiveness of training communication and emotional skills on parenting stress of mothers with autism children. Zanko Journal of Medical Sciences. 2017;18(56):111.

4. Astill RG, Van der Heijden KB, Van ljzendoorn $\mathrm{MH}$, Van Someren EJ. Sleep, cognition, and behavioral problems in school-age children: a century of research meta-analyzed. Psychol Bull. 2012;138(6):1109-38. doi: 10.1037/a0028204.

5. Sarihi N, Pournesaei GS, Nikakhlagh M. [Effectiveness of group play therapy on behavior problems in preschool children]. Journal of Analytical-Cognitive Psychology. 2015;6(23):35-41. [Persian]. 
6. Saberi H. Epidemiology of emotional and behavioral disorders in elementary children. Applied Psychology. 2008;2(8):1934.

7. Hallahan DP, Kauffman JM, Pullen PC. Exceptional learners: An introduction to special education. Boston: Allyn and Bacon; 1997.

8. Ryan SM, Jorm AF, Lubman DI. Parenting factors associated with reduced adolescent alcohol use: a systematic review of longitudinal studies. Aust N Z J Psychiatry. 2010;44(9):77483. doi: 10.1080/00048674.2010.501759.

9. Mohammadzadeh A, Najafi M. The role of anxiety and depression in explanation of attention deficit disorders in primary school-age children. Journal of Clinical Psychology. 2009;1(4):59-66. doi: 10.22075/jcp.2017.1987.

10. Fortin L, Lessard A, Marcotte D. Comparison by gender of students with behavior problems who dropped out of school. Procedia Soc Behav Sci. 2010;2(2):5530-8. doi: 10.1016/j. sbspro.2010.03.902.

11. Lubenko J, Sebre S. Longitudinal associations between adolescent behaviour problems and perceived family relationships. Procedia Soc Behav Sci. 2010;5:785-90. doi: 10.1016/j.sbspro.2010.07.185

12. Goddard N. Child and adolescent psychiatry. In: Wright PSJ, Phelan M, eds. Philadelphia: W.B. Saunders; 2000:169-70.

13. Jari M, Kelishadi R, Ardalan G, Taheri M, Taslimi M, Motlagh ME. Prevalence of behavioral disorders in iranian children. Health System Research. 2016;12(1):109-13.

14. Cerel J, FristadMA, VerducciJ, Weller RA, Weller EB. Childhood bereavement: psychopathology in the 2 years postparental death. J Am Acad Child Adolesc Psychiatry. 2006;45(6):68190. doi: 10.1097/01.chi.0000215327.58799.05.

15. Rossello J, Bernal G, Rivera-Medina C. Individual and group CBT and IPT for Puerto Rican adolescents with depressive symptoms. Cultur Divers Ethnic Minor Psychol. 2008;14(3):234-45. doi: 10.1037/1099-9809.14.3.234.

16. Franklin ME, Kratz HE, Freeman JB, Ivarsson $\mathrm{T}$, Heyman I, Sookman D, et al. Cognitive-behavioral therapy for pediatric obsessive-compulsive disorder: Empirical review and clinical recommendations. Psychiatry Res. 2015;227(1):78-92. doi: 10.1016/j.psychres.2015.02.009

17. Qutaiba A. Cognitive behavioral intervention in dealing with school violence among Arab Palestinian adolescents in Israel. Procedia Soc Behav Sci. 2010;5:1317-25. doi: 10.1016/j. sbspro.2010.07.282.

18. Kopacz KA. Effects of sensory integration on behavior maintained by automatic reinforcement. Boston, Massachusetts: Northeastern University; 2010.

19. Jagiellowicz J, Xu X, Aron A, Aron E, Cao G, Feng T, et al. The trait of sensory processing sensitivity and neural responses to changes in visual scenes. Soc Cogn Affect Neurosci. 2011;6(1):38-47. doi: 10.1093/scan/nsq001.

20. Eskandari B, Pouretemad H, Habibi Asgarabad M, Mazaheri Tehrani MA. Effect of Sensory Processing Style Interventions on increasing parental self-efficacy and child-parent relationship in children with autism. Journal of Exceptional Education. 2016;1(138):14-21.

21. Brown C, Dunn W. Adolescent-adult sensory profile: user's manual. San Antonio: Therapy Skill Builders; 2002.

22. Baker AE, Lane A, Angley MT, Young RL. The relationship between sensory processing patterns and behavioural responsiveness in autistic disorder: a pilot study. J Autism Dev Disord. 2008;38(5):867-75. doi: 10.1007/s10803-007-04590.

23. Roberts JE, King-Thomas L, Boccia ML. Behavioral indexes of the efficacy of sensory integration therapy. Am J Occup Ther. 2007;61(5):555-62.

24. Liss M, Timmel L, Baxley K, Killingsworth P. Sensory processing sensitivity and its relation to parental bonding, anxiety, and depression. Pers Individ Dif. 2005;39(8):142939. doi: 10.1016/j.paid.2005.05.007.

25. Pluess M, Boniwell I. Sensory-Processing Sensitivity predicts treatment response to a school-based depression prevention program: Evidence of Vantage Sensitivity. Pers Individ Dif. 2015;82:40-5. doi: 10.1016/j.paid.2015.03.011.

26. Dehghan F. Sensory Processing and Behavior. Journal of Exceptional Education. 2016;5(142):11-7.

27. Molagholamreza Tabasi F, Aliabadi F, Alizade Zarei M, Qorbani M, Rostami R. The relationship between behavioral problems and sensory processing in children with Attention Deficit/Hyperactivity Disorder (ADHD). Middle Eastern Journal of Disability Studies. 2016;6:282-7.

28. Zareh M, Ahmadi S. The Effectiveness of Cognitive-Behavioral Play Therapy on decreasing behavior problems in children. Applied Psychology. 2007;1(3):18-28.

29. Achenbach TM, Edelbrock CS. Manual for the youth self-report and profile. Vermont: University of Vermont, Department of Psychiatry; 1987

30. Minaee A. Adaptation and standardization Achenbach child behavior questionnaire, self-report and teacher report. Research on Exceptional Children. 2006;19(1):529-58.

31. Gallagher HM, Rabian BA, McCloskey MS. A brief group cognitive-behavioral intervention for social phobia in childhood. J Anxiety Disord. 2004;18(4):459-79. doi: 10.1016/s0887-6185(03)00027-6.

32. Spence SH, Donovan C, Brechman-Toussaint M. The treatment of childhood social phobia: the effectiveness of a social skills training-based, cognitive-behavioural intervention, with and without parental involvement. J Child Psychol Psychiatry. 2000;41(6):713-26

33. Mahmoodi N, Abdollahi MH, Shahgholian M, Gohari S. Mediating role of the positive and negative affect on the relationship between Sensory Processing Sensitivity and alexitimiya. Social Cognition. 2015;4(7):28-40.

34. Rathod VJ, Shah V, Alagesen J, Paranthaman P, Soundararajan P. Effect of sensory integration therapy and cognitive behavioral therapy on attention deficit hyperactivity disorder: single blinded study. Int J Physiother Res. 2015;3(2):947-54. doi: 10.16965/ijpr.2015.112. 